\title{
Determination of Trace Level of cAMP in Locusta Migratoria Manilensis Meyen by HPLC with Fluorescence Derivation
}

\author{
Lujun Zhang, Huiting Zhang, Jinfang Wang and Canping Pan* \\ College of Sciences, China Agricultural University, Beijing 100094, China. Tel.: (+86(10) 62733219, \\ Fax: +86 (10) 62733620, URL: http://www.cau.edu.cn/lxy
}

*Author to whom correspondence should be addressed. E-mail: campingp@cau.edu.cn

Received: 2 March 2006, in Revised Form: 30 May 2006 / Accepted: 21 July 2006 / Published: 9 August 2006

\begin{abstract}
A sensitive and rapid method was developed for the determination of cAMP in Locusta migratoria manilensis Meyen by high-performance liquid chromatography with fluorescence detection. The cAMP was derivatized using chloroacetaldehyde and TBAS buffer/methanol was used as the mobile phase. A detection quantification of $40 \mathrm{fmol} / \mathrm{ml}$ could be achieved when using fluorescence detection. An HPLC-MS method using DMHA as an ion-pair agent to analyze cAMP was also demonstrated. We studied the effect of dopamine and other stimulants on cAMP levels from isolated locust central nervous systems. The new method is well suited for the analysis of cAMP in small biological samples.
\end{abstract}

Keywords: cAMP; OA; Locusta migratoria manilensis Meyen; HPLC; HPLC-MS; fluorescence derivation; DMHA; TBAS.

\section{Introduction}

Adenosine $3^{\prime}, 5^{\prime}$-cyclic monophosphate (cAMP), as the ubiquitous intracellular second message, serves diverse functions in both vertebrates and invertebrates. The cAMP signal pathway can transfer extracellular to intracellular signals through membranes. Some specific receptor activation G-proteins regulate intracellular cAMP levels via their interaction with adenylate cyclase (AC). Intracellular cAMP levels then regulate protein kinase A (PKA) activity and PKA in turn regulates specific gene transcription factors to modulate functions in the cell. So the determination of cAMP has great practical importance for pharmaceutical and biomedical research. Locusta migratoria manilensis 
Meyen is a species of locust living in East Asia. It can flight from one country to another to eat crops and is one of the most dangerous pests for plants. Its central nervous system (CNS) has octopamine (OA) receptors that could stimulate the activation of adenylate cyclase leading to an increase the cAMP level. We tested the adenylate cyclase assays reaction from isolated locust central nervous systems. Because the OA receptor doesn't exist in the human body, the pesticides would be harmless to human if the target of some pesticides was the OA receptor. Thus, this test was developed for the selection of new compounds as pesticides.

The cAMP detection limit of traditional high-performance liquid chromatography (HPLC) methods is about $1 \mathrm{pmol} / \mathrm{ml}$ [1], which doesn't fit the purpose of detecting about $0.05-20 \mathrm{pmol} / \mathrm{ml}$ level of insect extracts. A sensitive and rapid HPLC chromatography method was develop and the derivatization conditions were optimized in our laboratory. In this paper, we also studied different mobile phases to improve the detection limit for cAMP.

\section{Experimental}

Adenosine 3',5'-cyclic monophosphate (cAMP) sodium salt, tetra-butylammoniumhydrogensulfate (TBAS), dimethylhexylamine (DMHA), 2-mercaptoethanol, theophylline, and methanol were purchased from Sigma (St louis, MO, USA). EGTA, Tris-Base, $\mathrm{KH}_{2} \mathrm{PO}_{4}, \mathrm{KOH}, \mathrm{NaOH}, \mathrm{HCl}, \mathrm{MgCl}_{2}$ and chloroacetaldehyde were purchased from Beijing Chemical Reagents Company. The deionized water was produced from Millipore (AFAQ certificate $N^{\circ}$ Qual/1991/340 b). The locust samples were centrifuged with Sigma 3k15 (Made in Germany).

\subsection{Locusta migratoria manilensis Meyen samples}

Locusta migratoria manilensis Meyen samples were produced as follows: The operation was kept at $0^{\circ} \mathrm{C}$. The central nervous systems (CNS) of 20 locusts were homogenized in $6 \mathrm{ml}$ of $6 \mathrm{mM}$ Trismaleate buffer ( $\mathrm{pH}=7.4)$ containing $2.0 \mathrm{mM}$ EGTA and $1.0 \mathrm{mM}$ 2-mercaptoethanol. The homogenizer was motor-driven at $1500 \mathrm{r} / \mathrm{min}$ for 10 times. Then the homogenate was centrifuged at 15,000 rpm $(19,118 \mathrm{~g})$ for $20 \mathrm{~min}$. The pellet was suspended by hand in the same buffer and allowed to stand in an ice-bath for $15 \mathrm{~min}$. The suspension was centrifuged again at 19,118 $\mathrm{g}$ for $20 \mathrm{~min}$.

The pellet was re-suspended by hand in incubation buffer of $80 \mathrm{mM}$ Tris-maleate buffer $(\mathrm{pH} 7.4)$ containing $10 \mathrm{mM}$ theophylline, $8.0 \mathrm{mM} \mathrm{MgCl}$, $0.5 \mathrm{mM}$ EGTA and $1.0 \mathrm{mM}$ 2-mercaptoethanol. The incubation buffer $(140 \mu \mathrm{l})$ containing the locust central nervous systems was pre-incubated at $30^{\circ} \mathrm{C}$ for 15 min with $20 \mu \mathrm{l}$ of GTP $(1 \mathrm{mM}), 20 \mu \mathrm{l}$ of OA (Octopamine, $1 \mathrm{mM}$ ). The Adenylate cyclase reaction was initiated by the addition of $20 \mu \mathrm{l}$ of $20 \mathrm{mM}$ ATP. The reaction mixture was incubated at $30^{\circ} \mathrm{C}$ for $15 \mathrm{~min}$ and terminated by heating at $90^{\circ} \mathrm{C}$ for $2 \min [2]$.

The mixture was centrifuged at $15,000 \mathrm{~g}$ for $30 \mathrm{~min}$. Then $200 \mu \mathrm{l}$ of the supernatant was prepared for fluorescence derivatization. 


\subsection{Derivatization and Chromatography}

Both standard samples ( $200 \mu \mathrm{l}$ containing $1 \mathrm{fmol} / \mathrm{ml}$ to $1000 \mathrm{pmol} / \mathrm{ml} \mathrm{cAMP}$ ) and locust samples $(200 \mu \mathrm{l})$ were mixed with $20 \mu \mathrm{l}$ chloroacetaldehyde and $200 \mu \mathrm{l}$ of $1.0 \mathrm{M}$ acetate buffer $(\mathrm{pH}=4.5)$ and heated at $80^{\circ} \mathrm{C}$ for $30 \mathrm{~min}$. Then the samples were cool at $4^{\circ} \mathrm{C}$ immediately. The derivation reaction is shown as Figure 1.

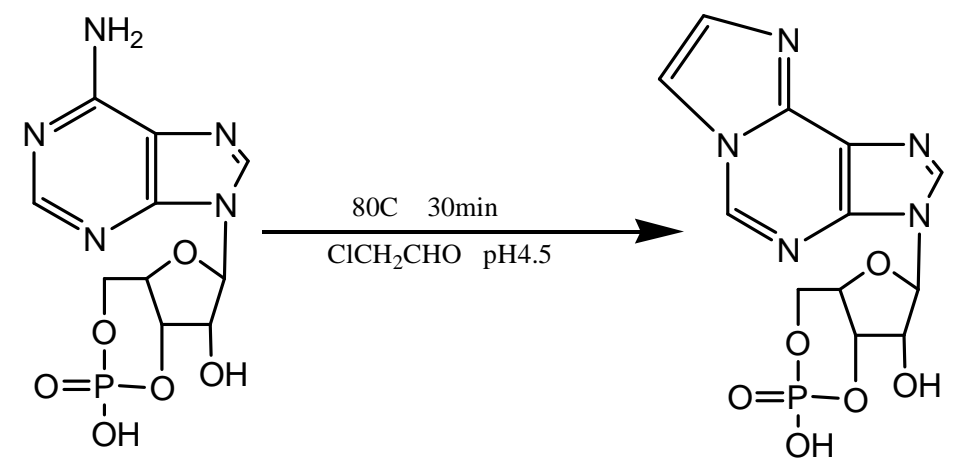

Figure 1. Derivatization reaction of cAMP by 2-chloroacetaldehyde.

LC pump: Waters 600 controller; Chromatography column: Waters SymmetryShield ${ }^{\mathrm{TM}}$ RP 18 $(150 \times 3.9 \mathrm{~mm}$ I.D., $5 \mu \mathrm{m}$, made in Ireland); Detector: Waters 2475 Multi $\lambda$ Fluorescence Detector (excitation wavelength: $280 \mathrm{~nm}$, emission wavelength: $420 \mathrm{~nm}$ ) and Waters 2996 Photodiode Array Detector; System controller: Empower Pro; Auto sampler: Waters 717 Plus Autosampler; Mobile

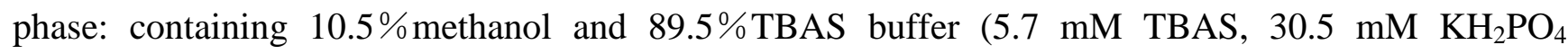
adjusted to $\mathrm{pH} 3.0$ with $1 \mathrm{M} / \mathrm{ml} \mathrm{KOH}$ ), Column temperature: $25^{\circ} \mathrm{C}$; Flow-rate: $1.0 \mathrm{ml} / \mathrm{min}$; Injection volume: $20 \mu \mathrm{l}$.

\section{Results and Discussion}

\subsection{Derivatization conditions}

We investigated the effect of reaction temperature and reaction time for the derivatization. Reaction temperature was varied from $60^{\circ} \mathrm{C}$ to $95^{\circ} \mathrm{C}$ and reaction time was varied from 30 min to $120 \mathrm{~min}$ (Figure 2). The highest detector response was obtained by heating at $80^{\circ} \mathrm{C}$ for $30 \mathrm{~min}$.

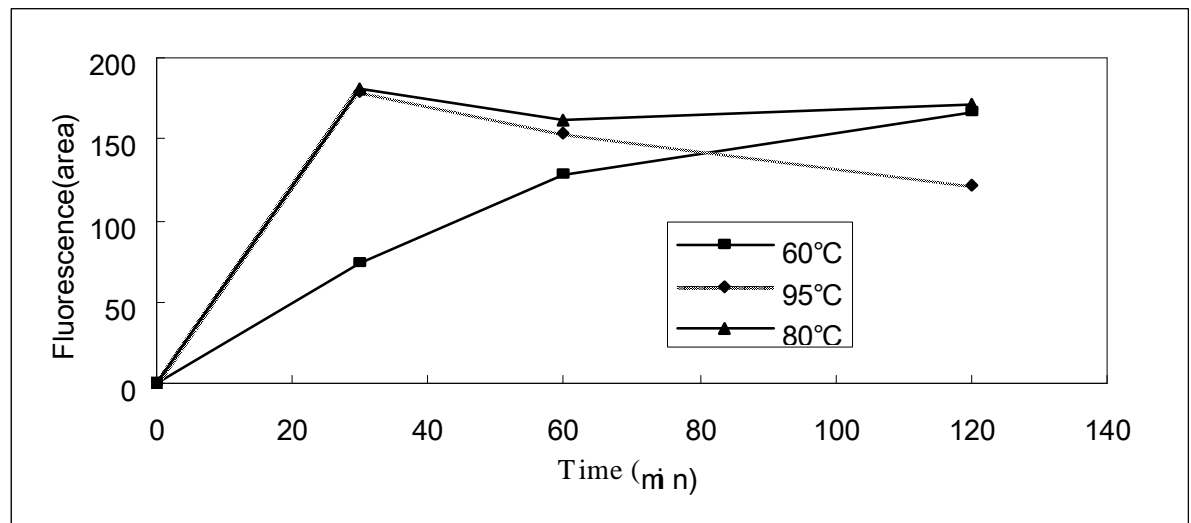

Figure 2. Effect of time and temperature on the derivatization reaction. 


\subsection{HPLC condition}

According to correlative reports, both the citric acid-dipotassium hydrogen phosphate and TBAS buffer could be used as mobile phase components for the detection of adenyl purines [1,3,4]. In order to improve the detection limit of cAMP, we compared the citric acid - dipotassium hydrogen phosphate buffer and the TBAS buffer and found the detection limit of cAMP superior using TBAS buffer as mobile phase. Meanwhile, we also considered other conditions (e.g., pH of mobile phase and the HPLC column). The use of mobile phase at $\mathrm{pH} 5.8$ as reported [4] was inferior to $\mathrm{pH}$ 3.0. LC columns, such as Agilent Zorbax Rapid Resolution $(15 \times 2.1 \mathrm{~mm}$ I.D., $3.5 \mu \mathrm{m})$, Agela Venusil MP-C18 $(150 \times 2.1$ mm I.D., $5 \mu \mathrm{m})$ and Waters SymmetryShield ${ }^{\mathrm{TM}}$ RP $18(150 \times 3.9 \mathrm{~mm}$ I.D., $5 \mu \mathrm{m}$, made in Ireland $)$ were evaluated and the Waters SymmetryShield ${ }^{\mathrm{TM}} \mathrm{RP} 18$ was found to be the most suitable for cAMP analysis. The cAMP detection limit when using the Waters SymmetryShield ${ }^{\mathrm{TM}}$ column was about 5.6 times lower than that of Agela Venusil MP and about 54.8 times lower than that of the Agilent Zorbax column. In order to enhance the sensitivity of Fluorescence detector, the attenuation value was set at 40 and the gain value was set at 1 .

\subsection{Calibration graphs}

Different concentration standard samples after derivatization (10 fmol/ml to $100 \mathrm{pmol} / \mathrm{ml} \mathrm{cAMP}$ ) were injected into HPLC. A typical chromatogram of cAMP in water $(1 \mathrm{pmol} / \mathrm{ml}, 0.1 \mathrm{pmol} / \mathrm{ml}$ and 0.01 $\mathrm{pmol} / \mathrm{ml}$ ) is shown in Figure 3. A chromatogram at the limit of detection in water for cAMP at 1 $\mathrm{fmol} / \mathrm{ml}$ is shown in Figure 4 and an example of a chromatogram of cAMP in the central nervous system (CNS) of locust using TBAS buffer with HPLC-FL is shown as Figure 5. Linear calibration curves ( $\mathrm{n}=4$ levels, $2 * 2$ injections) were obtained for cAMP at a concentrations ranging from 1-10 fmol $(\mathrm{y}=2085900 \mathrm{x}-414.5, \mathrm{R} 2=0.9997)$. Analytical recoveries were tested at two levels of $10 \mathrm{pmol} / \mathrm{ml}$ and $0.1 \mathrm{pmol} / \mathrm{ml}$ for a locust CNS blank in which the cAMP content was known. A typical chromatogram of $0.1 \mathrm{pmol} / \mathrm{ml}$ spiked in locust CNS blank is shown in Figure 6.

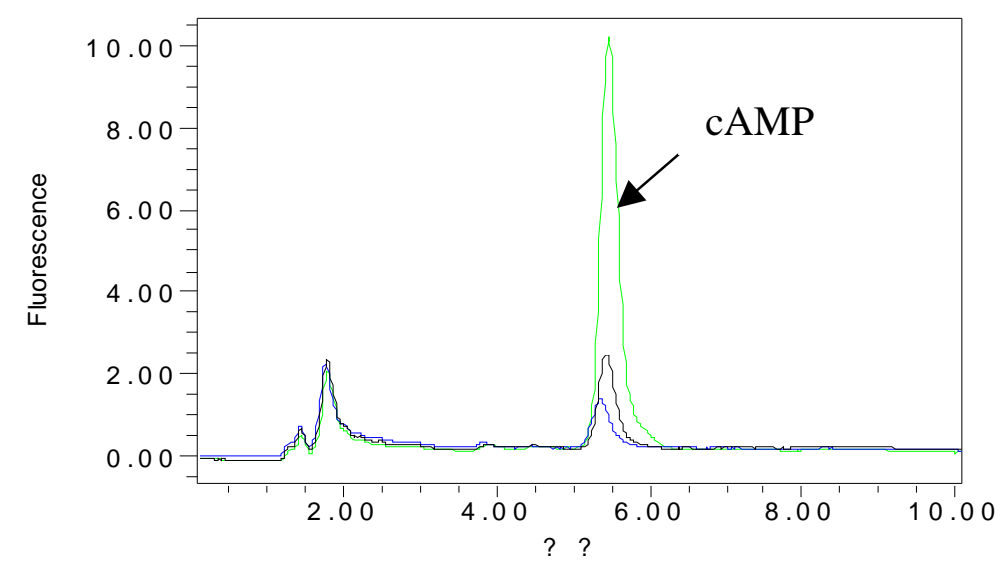

Figure 3. Chromatogram of cAMP ( $1 \mathrm{pmol} / \mathrm{ml}, 0.1 \mathrm{pmol} / \mathrm{ml}$ and $0.01 \mathrm{pmol} / \mathrm{ml})$ in water using TBAS buffer with HPLC-FL. 


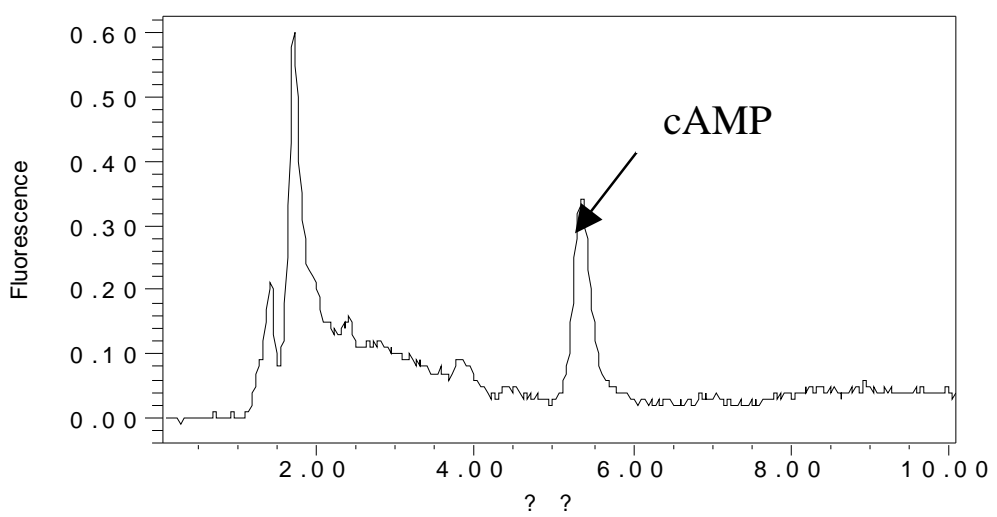

Figure 4. Chromatogram of cAMP (1fmol/ml) standard with HPLC-FL.

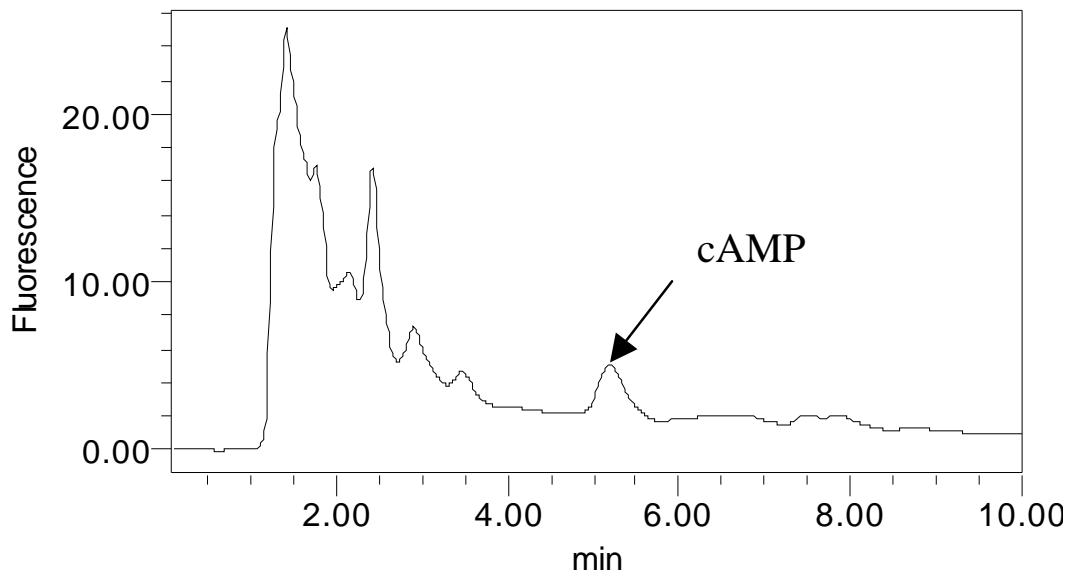

Figure 5. Chromatogram of cAMP determination in the CNS of locust using TBAS buffer with HPLC-FL.

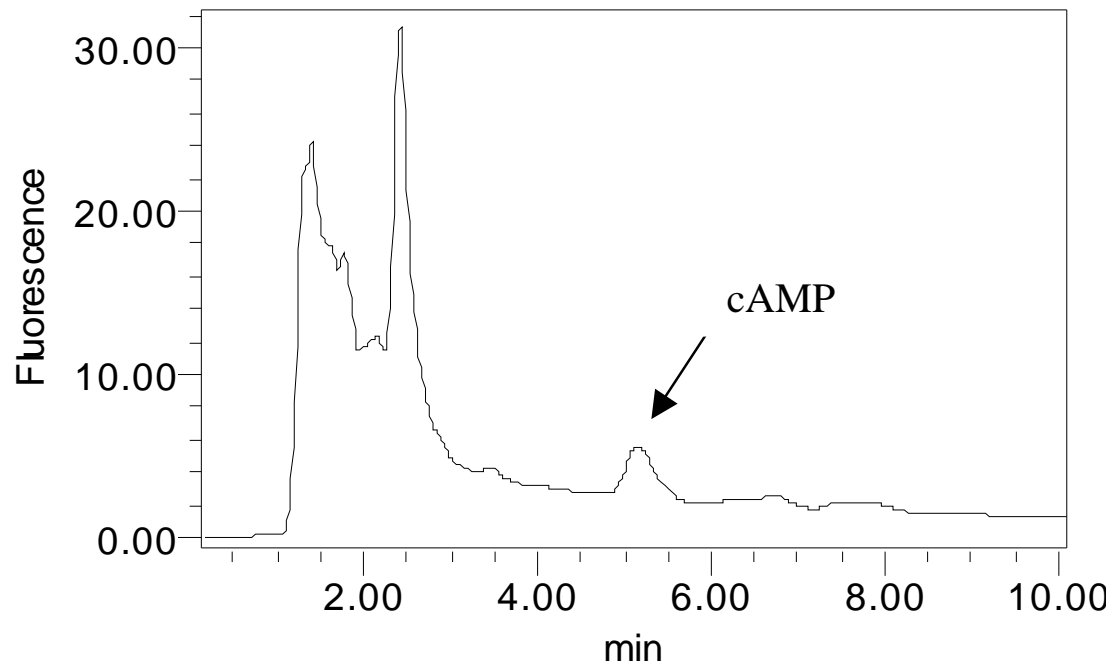

Figure 6. HPLC-FL chromatogram of a camp spike $(0.1 \mathrm{pmol} / \mathrm{ml})$ in a locust CNS. 


\subsection{Demonstration of cAMP with HPLC-MS}

As reported previously [5], DMHA is a better ion-pairing agent than tetra-alkyl ammonium salts for high-performance liquid chromatography-electrospray mass spectrometry (HPLC-MS) analysis of nucleosides and nucleotides. So we selected DMHA as an ion-pairing agent to analyze cAMP.

The instrumentation employed in this HPLC-MS method was an Agilent 1100 series LC-MSD Trap VL with a reversed-phase column (Agilent Eclipse XDB C18 250×4.6 mm I.D., $5 \mu \mathrm{m}$ ). The temperature of the column was set at $25^{\circ} \mathrm{C}$ and the volume of injection was $5 \mu 1$. The mobile phase consisted of eluent $\mathrm{A}$, a solution of $8 \mathrm{mM}$ DMHA adjusted to $\mathrm{pH} 3.5$ with formic acid, and eluent $\mathrm{B}$, was acetonitrile. The flow-rate was $0.8 \mathrm{ml} / \mathrm{min}$. The gradient program was as Table 1 .

Table 1. The HPLC gradient program with DMHA buffer.

\begin{tabular}{|l|l|l|}
\hline Time(min) & A\% & B\% \\
\hline 0.0 & 95 & 5.0 \\
\hline 6.0 & 35.0 & 65.0 \\
\hline 8.0 & 35.0 & 65.0 \\
\hline 9.0 & 5.0 & 95.0 \\
\hline 13.0 & 5.0 & 95.0 \\
\hline 14.0 & 95.0 & 5.0 \\
\hline
\end{tabular}

The effluent from the HPLC column was diverted to waste during the initial 6 min, then to the MS ion source to avoid background interference and contamination of the MS spectrometer by the nonvolatile salts. After 9 min the effluent was diverted to waste again.

We studied the negative (-) ionization mode and the positive (+) ionization mode with HPLC-MS or HPLC-MS ${ }^{2}$, and found that the negative (-) ionization mode was better suited for the analysis of cAMP. But limit of detection obtained was not as good as that obtained using HPLC-FL with TBAS buffer. Thus, we used HPLC-MS solely to confirm the cAMP in the sample. The MS conditions were as the follows: ion polarity: negative (-); ion source: ESI; drying temp: $350{ }^{\circ} \mathrm{C}$; nebulizer: 20.00 psi; drying gas: 4.0L/min; trap drive: 52.4; scan: 70-650 m/z.

Both total ion chromatogram (TIC) and extracted ion chromatogram (EIC) modes were studied. A typical chromatogram of $100 \mathrm{pmol} / \mathrm{ml}$ of $3^{\prime}, 5^{\prime}$-cAMP with total ion chromatogram mode is shown in Figure 7. We extracted $134 \mathrm{~m} / \mathrm{z}$ from $328 \mathrm{~m} / \mathrm{z}$ with HPLC-MS ${ }^{2}$ mode, and its chromatogram is shown in Figure 8. 

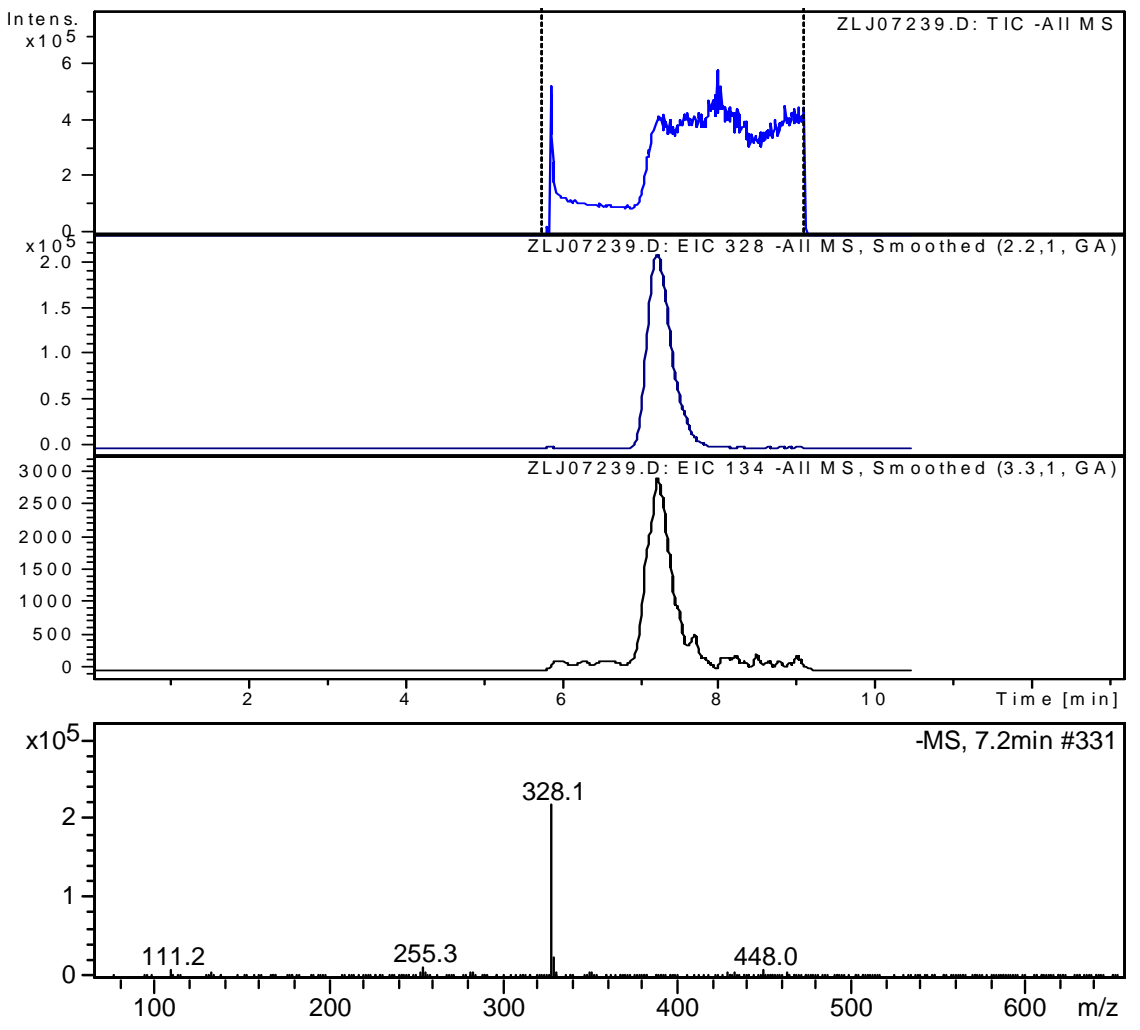

Figure 7. Typical chromatogram of $100 \mathrm{pmol} / \mathrm{ml} \mathrm{3} 3^{\prime}, 5^{\prime}$-cAMP with HPLC-MS TIC mode.
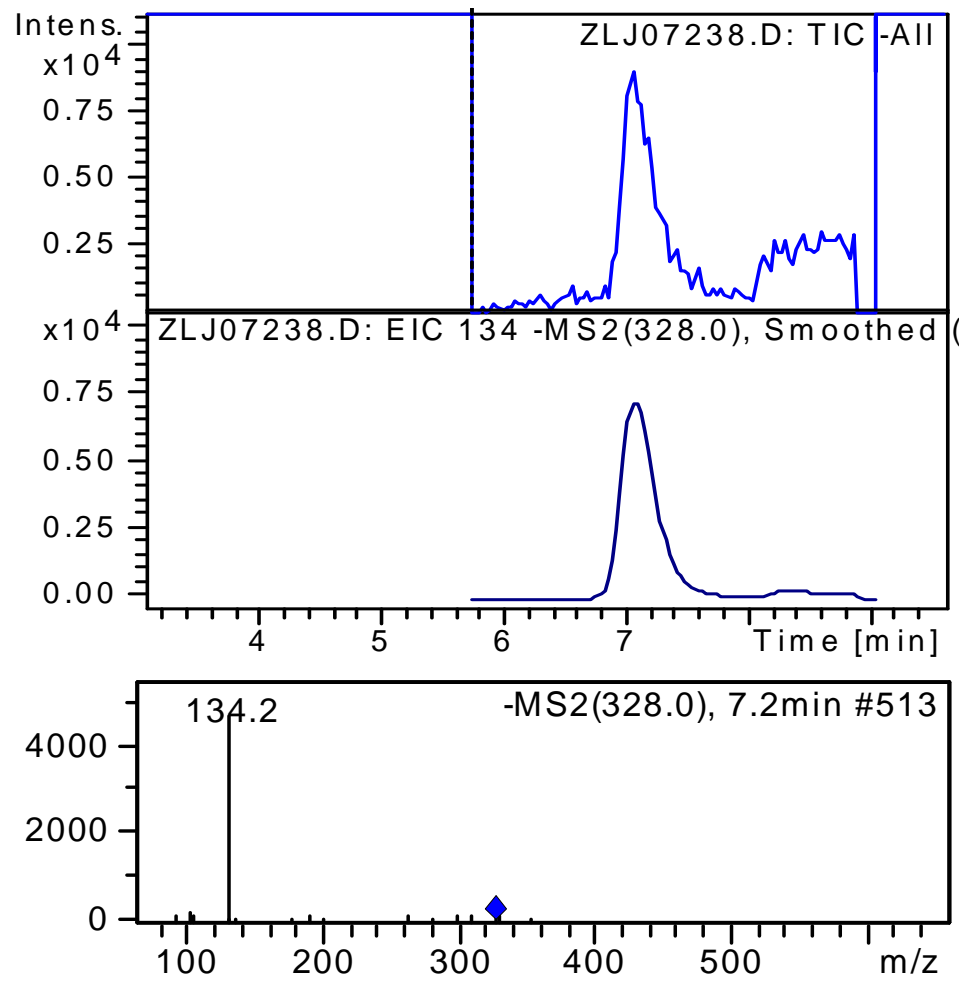

Figure 8. Typical chromatogram of $100 \mathrm{pmol} / \mathrm{ml} \mathrm{3}^{\prime}, 5^{\prime}$-cAMP with HPLC-MS EIC mode. 


\subsection{The assay of cAMP from locust}

The biogenic amine OA has a prominent role in insects and other invertebrates as it is involved in the regulation of multiple physiological events [6]. OA can stimulate the activation of adenylate cyclase leading to an increase in cAMP [2]. The CNS of invertebrates has the receptor of OA, so we anatomized the Locusta migratoria manilensis Meyen to gain access to their CNS. Then we homogenized and centrifuged the CNS to get the receptor of OA. Finally, we added GTP, OA and ATP to start the Adenylate cyclase assays reaction and by the action of Adenylate cyclase, ATP was transformed to cAMP.

The basal content of cAMP without OA was $0.42 \pm 0.01$ pmol/locust. With $1 \mathrm{mM} \mathrm{OA}$, the cAMP concentration reached to $1.51 \pm 0.01 \mathrm{pmol} /$ locust. The recoveries of cAMP $(10 \mathrm{pmol} / \mathrm{ml})$ in locust CNS were $100.3 \pm 0.6 \%$ and the recoveries of $0.1 \mathrm{pmol} / \mathrm{ml} \mathrm{cAMP}$ were $88.5 \% \pm 2.6 \%$. The limit of quantitation (LOQ) of this method $(\mathrm{S} / \mathrm{N}>10)$ was about $40 \mathrm{fmol} / \mathrm{ml}$ in locust sample. Using this method, we could analyze the effects of OA, OA agonists and OA antagonists in invertebrates to develop the new pesticides.

\section{Acknowledgements}

The authors thank Dr. Long Zhang to provide Locusta migratoria manilensis Meyen. This work was supported by Beijing National Foundation of Science (Grant No. 6042018).

\section{References and Notes}

1. Katayama, M.; Matsuda, Y.; Shimokawa, K.; Tanabe, S.; Kaneko, S.; Hara, I.; Sato, H. Simultaneous determination of six adenyl purines in human plasma by high-performance liquid chromatography with fluorescence derivatization. J. Chromatogr. B 2001, 760, 159-163.

2. Pan, C.; Chen, F.; Ozoe, Y. Stimulation and Attenuation Effects of Neuroactive Amines on cAMP Production in Two-spotted Mites Membranes. Elec. J. Biology 2005, 1, 3-5.

3. Dyckmans, J.; Raubuch, M. A modification of a method to determine adenosine nucleotides in forest organic layers and mineral soils by ion-paired reversed-phase high-performance liquid chromatography. J. Microbiol. Methods 1997, 30, 13-20.

4. Haink, G.; Deussen, A. Liquid chromatography method for the analysis of adenosine compounds. J. Chromatogr. B 2003, 784, 189-193.

5. Fung, E.N.; Cai, Z.W.; Burnette, T.C.; Sinhababu, A.K. Simultaneous determination of Ziagen and its phosphorylated metabolites by ion-pairing high-performance liquid chromatography-tandem mass spectrometry. J. Chromatogr. B 2001, 754, 285-295.

6. Bischof, L.J.; Enan, E.E. Cloning, expression and functional analysis of an octopamine receptor from Periplaneta Americana. Insect Biochem. Molec. Biol. 2004, 34, 511-521.

(C) 2006 by MDPI (http://www.mdpi.org). Reproduction is permitted for noncommercial purposes. 